\title{
Recurrent Attacks of Myoclonus in an Old Man Taking Sildenafil
}

\author{
Kyoo Ho Cho, Kyoung Heo*, Su Jin Chung, Yang-Je Cho and Byung In Lee
}

Department of Neurology, Epilepsy Research Institute, Yonsei University College of Medicine, Seoul, Korea

\begin{abstract}
Sildenafil, a medication for treatment of erectile dysfunction, is commonly used these days. Its side effect in nervous system such as seizure and myoclonus are known to be rare. A 74-year old man developed multifocal myoclonus 12 hours after taking sildenafil. Electroencephalography (EEG) showed spike discharges and on the other day. The symptom resolved two days after, and spike discharges on EEG also disappeared. 8 years before, he had experienced the same symptom after taking sildenafil. We report a case of myoclonus as a possible side effect of sildenafil and the EEG finding suggests that myoclonus associated with sildenafil is of cortical origin.
\end{abstract}

\section{Keywords: Sildenafil; Myoclonus; Seizure, EEG}

\section{Introduction}

Sildenafil is widely used to treat male erectile dysfunction. Two cases of men who developed Generalized TonicClonic Seizures (GTCS) after taking sildenafil have been reported previously, suggesting its proconvulsant effect [1]. Of 33,724 people who had side effects while taking sildenafil, eight (0.02\%) experienced myoclonus [2]. Further information except for the age ( $\geq 60$ years), the duration of taking, and concomitant conditions and drugs is not available. We describe the case of a man who developed myoclonus after taking sildenafil and discuss a probable mechanism for generation of myoclonus.

\section{Case Report}

A 74-year-old man developed myoclonus 12 hours after taking sildenafil $(25 \mathrm{mg})$. He had experienced the same symptom 8 years prior. After that episode he had not taken sildenafil because of concern regarding the recurrence of myoclonus. On presentation, he reported that erection occurred 1 hour after taking sildenafil and was maintained for 1 hour. The patient did not take any concomitant medication. Twelve hours later, continuous irregular multifocal myoclonic jerks occurred, involving all extremities, trunk, and head without mentalstatus changes, which severely impaired his normal activity. He did not have any other medical illness nor was he taking any other medication. Electroencephalography (EEG) was performed 16 hours after the onset of myoclonus, showing intermittent widespread spike discharges that did not have any temporal relationship with myoclonic jerks (Figure 1). Myoclonus gradually diminished and disappeared 38 hours after onset. EEG 4 hours after the disappearance of myoclonus was normal.
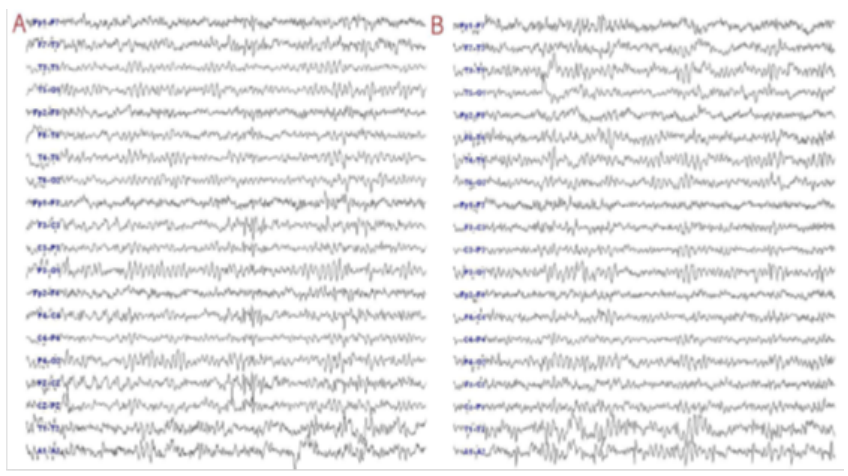

Figure 1: (A) EEG showing widespread spike discharges with frontal emphasis. (B) EEG showing no epileptiform discharges 4 hours after disappearance of myoclonus.

\section{Discussion}

In young men, the $t 1 / 2$ of sildenafil's clearance from the plasma is 2.6 hours, and at 16 hours virtually no sildenafil can be detected in the plasma, while its clearance in the elderly is significantly delayed and it is still present at detectable levels 36 hours after administration [3]. In a study reporting sildenafil's proconvulsant effect in humans, GTCS in two men occurred 3 and 4.5 hours after taking sildenafil [1]. These results could explain the prolonged duration of myoclonus, but not delayed onset in our case. Sildenafil's accumulative effect on an unknown receptor or substrate may be responsible for generation of myoclonus.

The influence of sildenafil on seizure activity in animal models was widely investigated. The mechanism of its proconvulsant activity has not been precisely delineated, but seems to be connected with an enhancement of the nitric oxide effect upon $\gamma$-aminobutyric acid (GABA)-mediated neurotransmission [4]. Sildenafil induced proconvulsant effect in pentylenetetrazole (PTZ) and bicuculine (GABA receptor antagonists) models of clonic seizures, but not in GTCS [4]. On the other hand, sildenafil showed anticonvulsant activity in the maximal electroshock seizure threshold test and also potentiated anticonvulsant activity of carbamazepine, valproate, and topiramate [5]. Sildenafil did not influence cocaine (increasing concentration of monoamines in the synaptic cleft)-induced clonic seizures [6], while it reversed anticonvulsive properties of diazepam, a $\mathrm{GABA}_{\mathrm{A}}$ receptor agonist in PTZ-induced clonic seizures [7]. When given concomitantly with ethosuximide, a T-type calcium channel blocker or vigabatrin, an inhibitor of GABA transaminase increasing GABA concentration, sildenafil enhanced their anticonvulsant effect against PTZ-induced clonic seizures $[8,9]$. In summary, sildenafil may have anticonvulsant activity in GTCS or GTS, but proconvulsant activity in clonic seizures. Myoclonus associated with sildenafil may be related to its effect on the $\mathrm{GABA}_{\mathrm{A}}$ receptor.

This case report suggests that physicians should recognize myoclonus as a side effect of sildenafil, and that myoclonus associated with sildenafil is of cortical origin. People taking sildenafil, in particular,

*Corresponding author: Heo K, Department of Neurology, Yonsei University College of Medicine, 50-1 Yonsei-ro, Seodaemun-gu, Seoul 120-752, Korea, Tel: +82 22228 1607; Fax: +82 2393 0705; E-mail: kheo@yuhs.ac

Received May 22, 2015; Accepted July 08, 2015; Published July 13, 2015

Citation: Cho KH, Heo K, Chung SJ, Cho YJ, Lee BI (2015) Recurrent Attacks of Myoclonus in an Old Man Taking Sildenafil. J Clin Case Rep 5: 556. doi:10.4172/2165-7920.1000556

Copyright: ( $) 2015 \mathrm{Cho} \mathrm{KH}$, et al. This is an open-access article distributed under the terms of the Creative Commons Attribution License, which permits unrestricted use, distribution, and reproduction in any medium, provided the original author and source are credited. 
Citation: Cho KH, Heo K, Chung SJ, Cho YJ, Lee BI (2015) Recurrent Attacks of Myoclonus in an Old Man Taking Sildenafil. J Clin Case Rep 5: 556. doi:10.4172/2165-7920.1000556

the first user should be given information about the possibility of myoclonus occurrence although it happens rarely. Sildenafil should not be prescribed to people who have experienced myoclonus related to the use of sildenafil.

\section{References}

1. Gilad R, Lampl Y, Eshel Y, Sadeh M (2002) Tonic-clonic seizures in patients taking sildenafil. BMJ 325: 869.

2. http://www.ehealthme.com/ds/viagra/myoclonus

3. Muirhead GJ, Wilner K, Colburn W, Haug-Pihale G, Rouviex B (2002) The effects of age and renal and hepatic impairment on the pharmacokinetics of sildenafil. Br J Clin Pharmacol 53 Suppl 1: 21s-30s.

4. Riazi K, Roshanpour M, Rafiei-Tabatabaei N, Homayoun H, Ebrahimi F, et al. (2006) The proconvulsant effect of sildenafil in mice: role of nitric oxide-cGMP pathway. Br J Pharmacol 147: 935-943.
5. Nieoczym D, Luszczki JJ, Czuczwar SJ, Wlaz P (2010) Effect of sildenafil on the anticonvulsant action of classical and second-generation antiepileptic drugs in maximal electroshock-induced seizures in mice. Epilepsia 51: 1552-1559.

6. Nieoczym D, Socala K, Wlaz P (2009) Lack of effect of sildenafil on cocaineinduced convulsions in mice. Pharmacol Rep 61: 930-934.

7. Gholipour T, Rasouli A, Jabbarzadeh A, Nezami BG, Riazi K, et al. (2009) The interaction of sildenafil with the anticonvulsant effect of diazepam. Eur J Pharmacol 617: 79-83

8. Nieoczym D, Socala K, Luszczki JJ, Czuczwar SJ, Wlaz P (2012) Influence of sildenafil on the anticonvulsant action of selected antiepileptic drugs against pentylenetetrazole-induced clonic seizures in mice. J Neural Transm 119: 923 931.

9. Nieoczym D, Socala K, Luszczki JJ, Czuczwar SJ, Wlaz P (2012) Sildenafi influences the anticonvulsant activity of vigabatrin and gabapentin in the timed pentylenetetrazole infusion test in mice. Prog Neuropsychopharmacol Biol Psychiatry 39: 129-135. 